\title{
Midazolam as an induction agent in comparison with propofol as a safe and effective alternative
}

\author{
Singh J. \\ Department of Anesthesia, Kathmandu University School of Medical Sciences \\ Correspondence address: Dr. Jeevan Singh, Department of Anesthesia, Kathmandu University School of Medical \\ Sciences, Dhulikhel, Kavre Nepal. \\ E-mail: docjeevan@yahoo.co.in, Mobile Number: 9851029933
}

\begin{abstract}
:
Introduction: Propofol produce rapid and smooth induction of anesthesia, with rapid metabolism, which would allow it to be used for the maintenance of anesthesia and free from the risk of anaphylactic reactions. Midazolam a new short acting water soluble Benzodiazepine with cardio vascular effects similar to that of diazepam may be an effective alternative for induction of anesthesia.
\end{abstract}

Methods: In this randomized study, all together 48 patients undergoing various surgical procedures belonging to Orthopedic, General Surgery and Gynecological Surgeries constituted the study group. Group-I (Midazolam Group) received intra-venous Midazolam $0.15 \mathrm{mg} / \mathrm{Kg}$ for induction of anesthesia and Group-II (Propofol Group) received $2 \mathrm{mg} / \mathrm{kg}$ intravenous Propofol for Induction of Anesthesia. Induction time, Heart Rate, Non invasive blood Pressure is recorded at 1minute interval for 5 minutes and after that at an interval for 5 minutes for another 30 minutes. Demographic data was analyzed by Student's t-test.

Results: The study showed no statistical significance in hemodynamic responses with either Midazolam or Propofol as an induction agent for General Anesthesia but there was statistically difference with respect to heart rate $(\mathrm{P}=0.001)$.

Conclusion: Midazolam was proven effective compared to Propofol as an induction Agent.

Keywords: Anesthesia, Midazolam, Propofol.

\section{Introduction}

An increasing interest in intra-venous anesthetics techniques has resulted from the availability of more efficacious intravenous agents due to the rising cost of traditional volatile agents and because of concern over anesthetics gas pollution in the operation room. An ideal intravenous anesthetic agent should relatively and pleasantly induce anesthesia in one arm brain circulation time. It should cause minimal cardiovascular and respiratory depression but should not cause drug interactions, excitatory phenomena, nausea, vomiting or toxicity. Various intravenous anesthetic agents have been introduced, but thiopentone sodium remains the gold standard while comparing with other agents. The main drawback of thiopentone sodium is its longer elimination half life. Thus, there is requirement of an anesthetic agent with short half life that will allow rapid recovery. For the day care surgery, the rapid recovery anesthetic agent is required. Propofol is the result of such a requirement which was introduced by department of clinical research at the laboratories of ICI pharmaceuticals. It has property of rapid and smooth induction, rapid metabolism and free from the risk of anaphylactic reactions. 1 Midazolam a new short 
acting water soluble Benzodiazepine with cardio vascular effects similar to that of diazepam may be an effective alternative for induction of anesthesia. Hence Midazolam is being evaluated as an induction agent in comparison with Propofol as a safe and effective alternative to Propofol.

\section{Methods}

This is the prospective, randomized and analytical study performed in the department of Anesthesiology in Dhulikhel Hospital, Dhulikhel, Kavre. The study population consisted of 48 patients undergoing various surgical procedures for Orthopedics Surgeries, General Surgeries and Gynecological Surgeries. The inclusion criteria was age group of 18-50 years, both the gender, ASA-I and II, weight of $35-75 \mathrm{kgs}$. The patient with uncontrolled Hypertension, Hypersensitivity to Benzodiazepines or propofol, Chronic Alcoholic or drug abuse, chronic consumption of Benzodiazepines, Pregnant or lactating women, hepatic and renal disease, epilepsy and any emergency surgeries were excluded. Patients were allocated randomly into one of the two groups Midazolam or Propofol Group.

Group-I received injection Midazolam $0.15 \mathrm{mg} / \mathrm{kg}$ and Group-II received Propofol $2 \mathrm{mg} / \mathrm{kg}$ for induction. All the patients received $5 \mathrm{mg}$ diazepam orally on the night before the surgery and injection Glycopyrrolate $0.2 \mathrm{mg}$ intramuscular (IM) one hour before the Surgery.

Group 1 (Midazolam Group) - consists of 24 patients both male and female. All the patients were pre-medicated with Injection Glycopyrrolate $0.2 \mathrm{mg}$ intramuscular (IM) one hour prior to induction of anesthesia received intravenous midazolam $0.15 \mathrm{mg} / \mathrm{kg}$ for induction of anesthesia.

Group 2 (Propofol Group) - Consist of 24 patients both male and female. All the patients were pre-medicated with injection Glycopyrrolate $0.2 \mathrm{mg}$ intramuscular (IM) one hour prior to induction of anesthesia received intravenous Propofol $2 \mathrm{mg} / \mathrm{kg}$ for induction of general anesthesia.

A thorough pre anesthetic evaluation was done a day before the surgery. All elective patients were taken into study, the as per protocol belonging to ASA grade - I and grade- II. The induction procedures were explained to them and informed consent was taken. An ethical approval for the study was taken from IRB-KUSMS/KU.

\section{Results}

In both Midazolam group and Propofol group 24 patients including 13 males and 11 females were enrolled for the study, both the groups were comparable with respect to sex.

The mean age in midazolam group was $32 \pm 6$ years(Mean \pm $\mathrm{SD})$ with the range of 18 to 40 years, the mean age in propofol group was $31 \pm 8$ (Mean $\pm \mathrm{SD}$ ) with a range of 22 to 40 years. $(\mathrm{P}<0.6)$.

The mean weight in Midazolam group was $53 \pm 11 \mathrm{kgs}$ (Mean \pm SD) was similar to the weight of patients in Propofol group with Mean \pm SD of $52 \pm 5 \mathrm{kgs}(\mathrm{P}<0.63)$

Systolic Blood Pressure (SBP), Diastolic Blood Pressure (DBP), Mean Blood Pressure (MBP) and Heart Rate (HR), were compared for both within the group and between the group changes.

In Midazolam group, pre-induction baseline systolic blood pressure (SBP) was $124 \pm 12 \mathrm{mmHg}($ Mean \pm SD), diastolic blood pressure (DBP) $80 \pm 8 \mathrm{mmHg}$, mean blood pressure (MBP) was $95+8 \mathrm{mmHg}(\mathrm{Mean} \pm \mathrm{SD})$ and heart rate was $95 \pm 15$ bpm $($ Mean \pm SD).(Table-1)

Table 1: Comparative study between baseline awake values

\begin{tabular}{|l|c|c|c|c|c|}
\hline $\begin{array}{c}\text { Pre induction } \\
\text { value }\end{array}$ & $\begin{array}{c}\text { Midazolam } \\
\text { Group }\end{array}$ & Range & $\begin{array}{c}\text { Propofol } \\
\text { Group }\end{array}$ & Range & p-value \\
\hline Heart rate (bpm) & $80 \pm 8$ & 66 to 117 & $78 \pm 7$ & 60 to 90 & 0.0001 \\
\hline SBP (mmHg) & $124 \pm 12$ & 100 to 158 & $124 \pm 13$ & 10 to 148 & 0.81 \\
\hline DBP (mmHg) & $80 \pm 8$ & 70 to 90 & $75 \pm 9$ & 50 to 98 & 0.05 \\
\hline MBP (mmHg) & $98 \pm 8$ & 80 to 107 & $90 \pm 9$ & 76 to 113 & 0.17 \\
\hline
\end{tabular}

In Propofol group, pre-induction, SBP was $124 \pm 13 \mathrm{mmHg}$. DBP was $75 \pm 9 \mathrm{mmHg}$, MBP was $98 \pm 8 \mathrm{mmHg}$ and heart rate was $95.29 \pm 14.8 \mathrm{bpm}(\mathrm{Mean} \pm \mathrm{SD})$. There was no statistically significant difference between the two groups with respect to $\operatorname{SBP}(p=0.81)$ DBP $(p=0.053)$ and MBP $(p=0.0001)$ but there was statitistically difference with respect to heart rate $(\mathrm{p}=0.0001)($ Table-1) 
Regarding systolic blood pressure, in Midazolam group the decrease in SBP from baseline was statistically significant at all points of time. $(\mathrm{P}<0.001)$. Likewise in Propofol group the decrease in SBP from baseline was statistically significant at all points of time. $(\mathrm{P}<0.001)$. SBP decreased in both the groups after induction from baseline awake values.

There was a statistically significant difference in the SBP at 2nd, 3rd, 4th, 5th and 15 th minutes after induction of anesthesia. The decrease in SBP was more in propofol group $(102 \pm 12 \mathrm{mmHg}$ and $113 \pm 11 \mathrm{mmHg})$ than in midazolam group (115 \pm 12 $\mathrm{mmHg}$ and $113 \pm 11 \mathrm{mmHg}$ ) at 2nd and 3rd minutes after induction of anesthesia. (Table -2$)$

Table 2: SBP

\begin{tabular}{|c|c|c|c|c|c|}
\hline \multirow[t]{2}{*}{ Time } & \multicolumn{2}{|c|}{ Midaszolam Group } & \multicolumn{2}{|c|}{ Propofol Group } & \multirow{2}{*}{$\begin{array}{l}\text { Between the } \\
\text { group p-value }\end{array}$} \\
\hline & Mean \pm SD & $\begin{array}{l}\text { Within * the } \\
\text { group p- value }\end{array}$ & Mean \pm SD & $\begin{array}{l}\text { Within } \sim \text { the } \\
\text { group p- value }\end{array}$ & \\
\hline Baseline & $124 \pm 12$ & - & $124 \pm 13$ & - & 0.92 \\
\hline $1^{\text {st }}$ minute & $116 \pm 13$ & 0.001 & $108 \pm 4$ & 0.0001 & 0.06 \\
\hline $2^{\text {nd }}$ minute & $115 \pm 12$ & 0.001 & $102 \pm 16$ & 0.0001 & 0.006 \\
\hline $3^{\text {rd }}$ minute & $113 \pm 11$ & 0.001 & $102 \pm 13$ & 0.0001 & 0.003 \\
\hline $4^{\text {th }}$ minute & $113 \pm 17$ & 0.001 & $105 \pm 13$ & 0.0001 & 0.042 \\
\hline $5^{\text {th }}$ minute & $111 \pm 16$ & 0.001 & $102 \pm 11$ & 0.0001 & 0.02 \\
\hline $10^{\text {th }}$ minute & $114 \pm 13$ & 0.001 & $106 \pm 20$ & 0.0001 & 0.09 \\
\hline $15^{\text {th }}$ minute & $114 \pm 11$ & 0.001 & $106 \pm 13$ & 0.0001 & 0.03 \\
\hline $30^{\text {th }}$ minute & $116 \pm 11$ & 0.001 & $110 \pm 13$ & 0.0001 & 0.09 \\
\hline
\end{tabular}

* When compared to baseline within the same group.

$\sim$ When compared between groups at a given point of time.

Regarding diastolic blood pressure, in midazolam group decreased following induction of anesthesia from a baseline value $80 \pm 8 \mathrm{mmHg}$ to $75 \pm 15 \mathrm{mmHg}$ by the end of 30 minutes. The decrease in DBP from baseline was statistically significant at all points of time except 15 th and 30 th minute $(\mathrm{P}<0.05)$.

In propofol group the decrease in DBP from baseline was statistically significant at all points of time. $(\mathrm{P}<0.0005)$

DBP decreased in both the groups after induction from baseline awake values. There was a statistically significant difference in the DBP changes at 3rd, 5th, 10th and15th $(\mathrm{P}<0.05)$ minutes of time after induction of anesthesia. (Table-3) 
Table 3: DBP

\begin{tabular}{|c|c|c|c|c|c|}
\hline \multirow[t]{2}{*}{ Time } & \multicolumn{2}{|c|}{ Midazolam } & \multicolumn{2}{|c|}{ Propofol } & \multirow{2}{*}{$\begin{array}{l}\text { Between the } \\
\text { group p-value }\end{array}$} \\
\hline & Mean \pm SD & $\begin{array}{l}\text { Within * the } \\
\text { group p- value }\end{array}$ & Mean \pm SD & $\begin{array}{l}\text { Within } \sim \text { the } \\
\text { group p- value }\end{array}$ & \\
\hline Baseline & $80 \pm 8$ & - & $75 \pm 9$ & - & 0.04 \\
\hline $1^{\text {st }}$ minute & $72 \pm 16$ & 0.0028 & $69 \pm 8$ & 0.0001 & 0.049 \\
\hline $2^{\text {nd }}$ minute & $72 \pm 14$ & 0.0031 & $66 \pm 6$ & 0.0001 & 0.06 \\
\hline $3^{\text {rd }}$ minute & $73 \pm 11$ & 0.0001 & $64 \pm 10$ & 0.0001 & 0.008 \\
\hline $4^{\text {th }}$ minute & $69 \pm 14$ & 0.0001 & $63 \pm 8$ & 0.0001 & 0.07 \\
\hline $5^{\text {th }}$ minute & $71 \pm 11$ & 0.0001 & $62 \pm 7$ & 0.0001 & 0.005 \\
\hline $10^{\text {th }}$ minute & $72 \pm 13$ & 0.0001 & $63 \pm 8$ & 0.0001 & 0.01 \\
\hline $15^{\text {th }}$ minute & $74 \pm 15$ & 0.0101 & $65 \pm 8$ & 0.0001 & 0.02 \\
\hline $30^{\text {th }}$ minute & $75 \pm 15$ & 0.0569 & $68 \pm 8$ & 0.0005 & 0.06 \\
\hline
\end{tabular}

* When compared to baseline within the same group.

$\sim$ When compared between groups at a given point of time.

Regarding MBP in Midazolam group, the decrease in MBP was statistically significant at all points of time except at 30th minute $(\mathrm{P}<0.001)$. In Propofol group the decrease in MBP from baseline was statistically significant at all points of time. $(\mathrm{P}<0.001)$.There was a statistically significant difference in the MBP at all points of time except 1 st minute after induction of anesthesia. (Table-4). The maximum decrease in MBP after induction of anesthesia in Propofol group was $76 \pm 6 \mathrm{mmHg}$ in 5 th minute. There was statistically significant difference in maximum decrease in MBP after induction from Base line awake value between the two groups. Time at which the maximum decrease in MBP after induction occurred in Midazolam group and propofol group was at 5th minutes, which was statistically significant. (Table-4)

Table 4: MBP

\begin{tabular}{|c|c|c|c|c|c|}
\hline \multirow[t]{2}{*}{ Time } & \multicolumn{2}{|c|}{ Midazolam Group } & \multicolumn{2}{|c|}{ Propofol Group } & \multirow{2}{*}{$\begin{array}{l}\text { Between the } \\
\text { group p-value }\end{array}$} \\
\hline & Mean \pm SD & $\begin{array}{l}\text { Within * the } \\
\text { group p- value }\end{array}$ & Mean \pm SD & $\begin{array}{l}\text { Within } \sim \text { the } \\
\text { group p- value }\end{array}$ & \\
\hline Baseline & $95 \pm 8$ & - & $92 \pm 9$ & - & - \\
\hline $1^{\text {st }}$ minute & $86 \pm 13$ & 0.001 & $82 \pm 7$ & 0.001 & 0.055 \\
\hline $2^{\text {nd }}$ minute & $86 \pm 12$ & 0.001 & $78 \pm 8$ & 0.001 & 0.006 \\
\hline $3^{\text {rd }}$ minute & $86 \pm 9$ & 0.001 & $77 \pm 10$ & 0.001 & 0.003 \\
\hline
\end{tabular}




\begin{tabular}{|c|c|c|c|c|c|}
\hline \multirow{2}{*}{ Time } & \multicolumn{2}{|c|}{ Midazolam Group } & \multicolumn{2}{c|}{ Propofol Group } & $\begin{array}{c}\text { Between the } \\
\text { group p-value }\end{array}$ \\
\cline { 2 - 5 } & Mean \pm SD & $\begin{array}{c}\text { Within * the } \\
\text { group p- value }\end{array}$ & Mean \pm SD & $\begin{array}{c}\text { Within } \sim \text { the } \\
\text { group p- value }\end{array}$ & 0.042 \\
\hline $4^{\text {th }}$ minute & $84 \pm 14$ & 0.001 & $77 \pm 8$ & 0.001 & 0.019 \\
\hline $5^{\text {th }}$ minute & $84 \pm 11$ & 0.001 & $76 \pm 6$ & 0.001 & 0.095 \\
\hline $10^{\text {th }}$ minute & $86 \pm 11$ & 0.001 & $77 \pm 11$ & 0.001 & 0.029 \\
\hline $15^{\text {th }}$ minute & $87 \pm 12$ & 0.001 & $79 \pm 8$ & 0.001 & 0.095 \\
\hline $30^{\text {th }}$ minute & $82 \pm 12$ & 0.007 & $82 \pm 8$ & & \\
\hline
\end{tabular}

* When compared to baseline within the same group.

$\sim$ When compared between groups at a given point of time.

In Midazolam group, pre-induction heart rate was $80 \pm 8 \mathrm{bpm}$. With induction of anesthesia there was no significant change in Heart Rate over the next 30 minutes.

In propofol group, Pre-induction Heart Rate was $78 \pm 7$ (Mean \pm SD) bpm. With induction of anesthesia there was no significant decrease in heart rate over the next 30 minutes. There was a highly significant difference in the heart rate changes between the two groups at all the points of time $(\mathrm{p}=0.0001)$. (Table-5)

Table 5: Heart Rate

\begin{tabular}{|l|c|c|c|c|c|}
\hline \multicolumn{1}{|c|}{ Time } & \multicolumn{2}{|c|}{ Midazolam Group } & \multicolumn{2}{c|}{ Propofol Group } & $\begin{array}{c}\text { Between the } \\
\text { group p-value }\end{array}$ \\
\cline { 2 - 5 } & Mean \pm SD & $\begin{array}{c}\text { Within * the } \\
\text { group p- value }\end{array}$ & Mean \pm SD & $\begin{array}{c}\text { Within } \sim \text { the } \\
\text { group p- value }\end{array}$ & - \\
\hline Baseline & $95 \pm 15$ & - & $78 \pm 7$ & - & 0.2 \\
\hline $1^{\text {st }}$ minute & $97 \pm 11$ & 0.32 & $76 \pm 8$ & 0.38 & 0.0001 \\
\hline $2^{\text {nd }}$ minute & $97 \pm 14$ & 0.44 & $76 \pm 9$ & 0.45 & 0.0001 \\
\hline $3^{\text {rd }}$ minute & $95 \pm 11$ & 0.83 & $76 \pm 10$ & 0.48 & 0.0001 \\
\hline $4^{\text {th }}$ minute & $93 \pm 11$ & 0.27 & $75 \pm 10$ & 0.17 & 0.0001 \\
\hline $5^{\text {th }}$ minute & $91 \pm 12$ & 0.05 & $76 \pm 7$ & 0.26 & 0.0001 \\
\hline $10^{\text {th }}$ minute & $91 \pm 12$ & 0.16 & $74 \pm 6$ & 0.04 & 0.0001 \\
\hline $15^{\text {th }}$ minute & $91 \pm 8$ & 0.08 & 0.10 & & 0.19 \\
\hline $30^{\text {th }}$ minute & $91 \pm 8$ & & & 0.0001 \\
\hline
\end{tabular}

* When compared to baseline within the same group.

$\sim$ When compared between groups at a given point of time. 
The incidence like cough was $12.5 \%(n=6)$ in Propofol group whereas it was $0 \%(\mathrm{n}=0)$ in midazolam group. The incidence of hiccough was $16.6 \%(\mathrm{n}=8)$ for midazolam group. Whereas it was $8.3 \%(n=4)$ in Propofol group had hiccough.

The mean induction time (sec) for Midazolam group was $31.16 \pm 1.73$ i.e. Mean \pm SD which was similar to the mean Induction time for Propofol group i.e. $31.29 \pm 1.98$ (mean \pm SD) which are statistically significant for both the groups. Mean Induction doses used were $7.96 \mathrm{mg}$ of Midazolam and $100 \mathrm{mg}$ of Propofol corresponding to $0.15 \mathrm{mg} / \mathrm{kg}$ and $2 \mathrm{mg} / \mathrm{kg}$ respectively. Apnea occurred in both the midazolam and Propofol groups, with no further need of extra dose of $25 \%(n=12)$ of induction dose.

Four patients in propofol group complained of mild pain at the site of injection of the drug which is $16.6 \%(n=8)$. Whereas only 2 patients complained of pain which is $8.3 \%$ $(n=4)$ in midazolam group. The incidence of side effects during induction was comparable between 2 groups and clinically significant.

The incidence of post operative complications were low in midazolam group only 2 patients in midazolam group had nausea which is $8.3 \%(\mathrm{n}=4)$, five patients in Propofol group had nausea which is $16.6 \%(\mathrm{n}=8)$

There was no incidence of vomiting in Midazolam group whereas 2 patients in Propofol group had an incidence of vomiting, the percentage of incidence of vomiting is $8.3 \%$ $(n=4)$ in propofol group where as it is Zero in midazolam group.

There was only one incidence of tenderness in Propofol group at injection site which accounts $4.2 \%(n=2)$ whereas it is $0 \%(n=0)$ in midazolam group.

The over all patient acceptances for the same anesthesia were also higher with midazolam. For $75 \%(n=36)$ in midazolam group it was a good acceptance whereas $8 \%$ $(n=3)$ in Propofol group accepted as good.

$54.2 \%(n=26)$ in Propofol group satisfied with the anesthesia whereas $25 \%(n=12)$ in midazolam group accepted as satisfactory.

\section{Discussion}

Propofol is the second most frequently used drug for induction of intravenous general anesthesia after thiopentone. There are however certain absolute contraindications for its use like Propofol sensitivity and shock. Due to its cardio-respiratory depressive effects, propofol is not the drug of choice in Shock patient or patients with cardio respiratory diseases, .Midazolam a new short acting water soluble Benzodiazepine with cardio vascular effects similar to that diazepam may be an effective alternative for induction of anesthesia.

This Study was done to evaluate the efficiency of Midazolam. In its ability to depress the central nervous system to ascertain whether it can be a safe and effective alteration of propofol.

In our study the demographic data were comparable for age, weight and sex in both the groups. As per our study, Systolic Blood Pressure (SBP), Diastolic Blood Pressure (DBP), Mean Blood Pressure (MBP) and Heart Rate (HR), were compared for both within the group and between the group changes.

Regarding systolic blood pressure, in Midazolam group the decrease in SBP from baseline was statistically significant at all points of time. $(\mathrm{P}<0.001)$. Likewise in Propofol group the decrease in SBP from baseline was statistically significant at all points of time. $(\mathrm{P}<0.001)$.

The finding of the present study resembles with the study carried out by Celebioglu B et al who concluded that there was no significant changes in SBP between two groups undergoing elective Coronary artery by-pass graft (CABG) ${ }^{2}$.Likewise similar study conducted by Reinhart DJ et al revealed no statistically significant differences between the regimens. ${ }^{3}$ The study carried by Kataria et al found that there was significantly lesser fall in SBP in propofol group compared to midazolam group. ${ }^{4}$

Regarding diastolic blood pressure, in midazolam group decreased following induction of anesthesia from a baseline value $80 \pm 8 \mathrm{mmHg}$ to $75 \pm 15 \mathrm{mmHg}$ by the end of 30 minutes. The decrease in DBP from baseline was statistically significant at all points of time except 15 th and 30th minute $(\mathrm{P}<0.05)$.In propofol group the decrease in DBP from baseline was statistically significant at all points of time. $(\mathrm{P}<0.0005)$

The finding of the present study resembles with the study carried out by Celebioglu B et al who concluded that there was no significant changes in DBP between two groups undergoing elective Coronary artery by-pass graft (CABG). ${ }^{2}$ Likewise similar study conducted by Reinhart DJ et al revealed no statistically significant differences between the regimens. ${ }^{3}$ The study carried by Kataria et al found that there was significantly lesser fall in DBP in propofol group compared to midazolam group. ${ }^{4}$

Regarding MBP in Midazolam group, the decrease in MBP was statistically significant at all points of time except at 30 th minute $(\mathrm{P}<0.001)$. In Propofol group the decrease in MBP from baseline was statistically significant at all points 
of time. ( $\mathrm{P}<0.001)$. There was a statistically significant difference in the MBP at all points of time except 1st minute after induction of anesthesia

The finding of the present study resembles with the study carried out by Celebioglu B et al who concluded that there was no significant changes in MBP between two groups undergoing elective Coronary artery by-pass graft (CABG). ${ }^{2}$ Likewise similar study conducted by Reinhart DJ et al revealed no statistically significant differences between the regimens. ${ }^{3}$ The study carried by Kataria et al found that there was significantly lesser fall in MBP in propofol group compared to midazolam group. ${ }^{4}$

In Midazolam group, pre-induction heart rate was $80 \pm 8$ $\mathrm{bpm}$. With induction of anesthesia there was no significant changes in Heart Rate over the next 30 minutes.

In propofol group, Pre-induction Heart Rate was $78 \pm 7$ $(\mathrm{Mean} \pm \mathrm{SD}) \mathrm{bpm}$. With induction of anesthesia there was no significant decrease in heart rate over the next 30 minutes. Brossy and coworker found that HR increased significantly above baseline after induction and intubation in both groups (propofol and thiopentone) but unlike our study in which significant differences between two groups existed, they observed no difference between the two groups. ${ }^{5}$

\section{Pain during Injection}

In the present study the incidence of pain during injection was slightly higher with propofol though it was not statistically significant. This correlates with reports by Conner et al 1978, Reeves SG et al 1997. 6,8 In midazolam $8.3 \%$ of patients had pain compared to $16.6 \%$ in the propofol group complained of pain on injection. No patients in midazolam group had cough at the same time $12.5 \%$ of patients in propofol group had cough the incidence of hiccough was $16.6 \%$ in midazolam group whereas only $8.3 \%$ of patients in propofol group had hiccough.

\section{Post Operative Features}

Midazolam was remarkably free of side effects. Only $8.3 \%$ of patients in midazolam had mild side effects like nausea whereas the incidence of nausea was $16.6 \%$ in propofol group.

There was no incidence of nausea and vomiting in patients belong to midazolam group. This incidence was $8.5 \%$ in propofol group. However Shah et al reported that nausea and vomiting was absent in propofol group compared to 6.67 in midazolom group. ${ }^{7}$

Only 1 out of 24 patients in propofol group had thrombophlebitis whereas there was no incidence of thrombophlebitis in midazolam group. Our finding resembles with Shah et al who reported that $3.3 \%$ of the propofol group had thrombophelbitis compard with $0 \%$ in madazolam group. ${ }^{7}$

Venous irritation at the site of injection was minimal in both groups. The incidence of thrombophlebitis was similar to that reported by Reves et al 1979, Reitan et al 1987, Abraham and Kaur 1997.8,9,10

Gamble et al 2001, found thrombosis and thrombophlebitis in 2 patients each after midazolam and propofol between 7-10 days after surgery, even though there was no sign of venous irritation in the first week. ${ }^{11}$

Patient acceptance of anesthesia was good in $75 \%$ patients in midazolam group whereas the patient's acceptance in propofol group was $45.8 \%$

Patient's acceptance of anesthesia was satisfactory in 54.2 in propofol whereas it was $25 \%$ in midazolam group. Overall although midazolam does not supersede propofol it certainly a useful hypnotic with a few advantages over propofol for induction and maintenance of balance anesthesia.

Conclusion:

In conclusion, midazolam caused no adverse hemodynamic changes at the time of induction and maintenance of anesthesia in ASA physical status I and II as compared to propofol. Hence midazolam was proven to be effective compared to propofol .

\section{References}

1. Aun C, Major E. The cardio respiratory effects of ICI 35868 in patients with heart disease. Anaesthesia 1984;39(11): 1096-1100.

2. Celebioglu B, Ercelen O, Pasaoglu I, Gol A, Aypar U, Erdem K. Comparision of midazolam and propofol during induction in elective CABG. Turk J Med Res 1994; 12 (2):66-69.

3. Reinhart DS, Grum DR, Berry J, Lensch D, Marchbanks CR, Zsigmond. Outpatient general Anaesthesia: a comparison of a combination of midazolam plus propofol and propofol alone. $\mathrm{J}$ Clin Anesth. 1997; 9(2): 130-7.

4. Roopam K, Ajay S, Sukirti P, Ishwar S. A comparative study of propofol auto-coinduction versus midazolam propofol co-induction using the priming principle. Indian journal of Anaesthesia.;2010: 54(6). 558-561

5. Brossy MJ, James MFM and Janicki PK. Hemodynamic and catecholamine changes after 
induction of anaesthesia with either thiopentone or propofol with suxamethonium. Br. J Anesthesia 1984; 72(7):596-598.

6. Conner JT, Katz RL, Pagano RR, Graham CW. RO 21- 398 for intravenous surgical premedication and induction of anaesthesia " Anaesth Analg 1978;57(1):1-5.

7. Shah PJ, Dubey KP, Watti C,Lalwan J . Effectiveness of thiopentone, propofol and midazolam as an ideal intravenous anaesthetic agent for modified electroconvulsive therapy: A comparative study. Indian Journal of Anesthesia 2010; 54(4):296-301.

8. Reves JG, Corssen G and Holcom C. Comparision of Midazolam and diazepam for induction of anaesthesia Canad. Anaesth Soc J 1978; 25(3):211-214.

9. Reitan J, Soliman JE. A comparsion of midazolam and diazepam for induction of anaesthesia in high risk patients. Anesth Intens Care 1987;15(2): 175178.

10. Abraham J and Kaur B. Evaluation of midazolam as an Intravenous Induction Agent for General Anaesthesia. Ind J Anaesth 1997;41(7):34-37.

11. Gamble JAS, Kawar P, Dundee JW, et al. Midazolam: an alternative to propofol? Br. J Anaesth 1985;57(1):97-99. 